\title{
DEMOCRACIA E REPRESENTAÇÃO LOCAL: PERFIS DE CARREIRA E PERCEPÇÕES POLÍTICAS DE VEREADORES DA GRANDE VITÓRIA (ES)
} Democracy and local representation: career profiles and policy perceptions of Grande Vitória (ES) councilors

\author{
Riberti de Almeida FELISBINO \\ CEET Vasco Coutinho, Vila Velha (ES), Brasil \\ ribertialmeida@hotmail.com \\ https://orcid.org/0000-0001-9267-443X (1) \\ Paulo Magalhães ARAÚJO \\ Departamento de Ciências Sociais, \\ Universidade Federal do Espírito Santo, Vitória (ES), Brasil \\ pauloaraujomagalhaes@gmail.com \\ http://orcid.org/0000-0002-2541-3640 잉
}

Mais informações da obra no final do artigo

\section{RESUMO}

O objetivo deste artigo é analisar os perfis de carreira e as percepções políticas dos vereadores dos municípios de Vitória, Vila Velha, Serra e Cariacica, Estado do Espírito Santo. O recorte temporal foi o ano de 2015 e a técnica de coleta e análise dos dados foi baseada nos principais métodos de pesquisa nas Ciências Sociais. O artigo é dividido em quarto dimensões: I) Pesquisa e metodologia, II) Atributos adscritos e adquiridos dos vereadores, III) Perfis de carreira e partidário dos parlamentares e IV) Percepções políticas dos vereadores. Na dimensão I apresentamos aspectos metodológicos da pesquisa. Com as dimensões II e III mostramos a existência de diversos filtros, possibilitando traçar sociologicamente a imagem do parlamentar municipal. Na dimensão IV constatamos, entre outras coisas, que o centro da escala ideológica é o que mais agrega os vereadores entrevistados, que a democracia brasileira é muito ou bastante estável e é preferível à formas não democráticas de governo.

PALAVRAS-CHAVE: Perfil de Carreira. Percepção Política. Vereador. Município. Elite Política.

\begin{abstract}
The objective of this paper is to analyze the career profile and the political perceptions of the council-man of the city Vitória, Vila Velha, Serra and Cariacica, State of Espírito Santo. 2015 was the year of data collection and the technique and analysis were based on research methods in the Social Sciences. The paper is divided into four dimensions: I) Research and methodology, II) Personal and acquired attributes of the council-man, III) Career and political profile of the parliamentarians, and IV) Political perceptions of the council-man. Dimension I presents methodological aspects of the research. Dimensions II and III show the various filters, making it possible to draw sociologically the image of the councilman. Dimension IV shows that the center of the ideological scale is what most aggregates councilors, that democracy is very or very stable and is preferable to undemocratic forms of government.

KEYWORDS: Career Profile. Political Perceptions. Council-Man. City. Political Elite.
\end{abstract}




\section{INTRODUÇÃO}

O atual desenho institucional do sistema político brasileiro combina 0 presidencialismo com um regime político democrático e um modelo de Estado federal. Tal formato também conta com a presença de um sistema eleitoral de representação majoritária, para o Executivo, e um sistema proporcional com lista aberta, para o Legislativo (exceto para o Senado, cujas eleições são, também, majoritárias). O sistema abriga, atualmente, 35 legendas partidárias (multipartidarismo) em constante disputa na arena eleitoral. No bicameralismo brasileiro, do total de 35 partidos, atualmente 28 têm assento na Câmara dos Deputados e 15 no Senado Federal. Essa combinação vêm promovendo uma série de discussões de natureza política e acadêmica a seu respeito, estimulando cada vez mais o interesse dos analistas para entender a lógica do seu funcionamento.

Esse interesse tem produzido inúmeros estudos sobre o desempenho das instituições que compõem o desenho atual, em especial dos poderes Executivo e Legislativo, seja na esfera nacional ou subnacional. A literatura neo-institucionalista destaca que as instituições são importantes na análise do sistema político e, consequentemente, temos que acrescentar que os membros das elites ${ }^{1}$ também são relevantes, pois são eles que dirigem as instituições. Scott Mainwaring (2003) destaca que a tarefa de compreender um sistema político torna-se mais difícil se os analistas não dão uma atenção especial aos membros das elites. Este artigo se dedicará ao estudo das elites na esfera subnacional, dando destaque especial ao âmbito municipal.

Os municípios brasileiros passaram, desde 1824 até 1988, por um processo de readaptação política, administrativa e econômica de suas instituições. A posição atual dos municípios é bem diversa da que ocuparam nos arranjos constitucionais anteriores. Comparado com o do período de 1946 a 1964, a autonomia municipal no atual regime democrático passou a ser exercida de direito e de fato nas administrações locais. Apesar da relevância que os municípios passaram a ter a partir da promulgação da Constituição

\footnotetext{
${ }^{1}$ Neste artigo a definição de elite apoia nos estudos históricos sobre elites e baseia-se no critério de posição. Segundo Charles Wright Mills, "la minoría poderosa está compuesta de hombres cuyas posiciones les permiten trascender los ambientes habituales de los hombres y las mujeres corrientes; ocupan posiciones desde las cuales sus decisiones tienen consecuencias importantes" (MILLS, 2001, p. 12). Devido aos postos que ocupam no seio da sociedade, eles têm uma forte influência sobre os demais atores envolvidos no jogo político.
} 
Federal de 1988, as referências e pesquisas sobre os vereadores são poucas, bem como disseram Rocha e Kerbauy:

Sabe-se pouco sobre a organização e a estrutura das Câmaras Municipais no Brasil. Espera-se que a enorme diversidade em termos de porte populacional e capacidade fiscal gerem perfis muito diferentes no formato e nos procedimentos das Câmaras e, logo, no grau de desenvolvimento institucional e modernização dessas instituições. Os esforços para superar a carência histórica de dados sobre o Legislativo local no país ainda não permitiram a elaboração de um quadro completo e representativo da estrutura e do funcionamento das Câmaras Municipais considerando-as em toda sua diversidade (KERBAUY, 2014, p. 28).

Este artigo tem o propósito de analisar os perfis de carreira e as percepções políticas dos vereadores dos municípios de Vitória, Vila Velha, Serra e Cariacica, Estado do Espírito Santo, e as principais indagações que orientam o artigo são: Quem nos governa? Que pessoas são essas que tomam as principais decisões no âmbito municipal? Qual o perfil delas? O que elas pensam da democracia? $\bigcirc$ artigo procura elucidar empiricamente estas indagações, para o debate sobre as elites parlamentares locais e o papel que desempenham na política municipal. Além desta introdução e da conclusão, i) abordamos o desenho da pesquisa que levou à produção do material empírico analisado (Dimensão I); ii) exploramos a caracterização social dos vereadores para identificar seus perfis (Dimensão II); iii) analisamos o processo de recrutamento dos parlamentares para conhecer os caminhos seguidos por eles (Dimensão III) e iv) examinamos a concepção de democracia para saber como os vereadores veem esse regime político (Dimensão IV).

\section{AS DIMENSÕES DAS ELITES PARLAMENTARES LOCAIS DA GRANDE VITÓRIA (ES)}

\subsection{Dimensão I: Pesquisa e metodologia}

Os dados que dão sustentabilidade ao artigo referem-se à pesquisa "Elites políticas parlamentares municipais da Grande Vitória (ES)"2, vinculada ao Núcleo de Pesquisa Social Aplicada da Universidade Vila Velha, realizada entre os meses de outubro e

\footnotetext{
${ }^{2}$ Registramos aqui nosso agradecimento a todos envolvidos na coleta e tratamento dos dados e na elaboração do relatório técnico. Também agradecemos a Mercatto Inteligência Competitiva pelo suporte técnico.
} 
novembro de 2015, que tratou de questões relativas aos vereadores de quatro municípios da Grande Vitória: Vitória, Vila Velha, Serra e Cariacica ${ }^{3}$.

O questionário utilizado teve como referência o formulário da pesquisa "Organização e funcionamento da política representativa no Estado de São Paulo (19942014)" coordenada pelas professoras Rachel Meneguello e Maria Teresa Micelli Kerbauy. Autorizado o uso do questionário, o mesmo passou por um processo de avaliação e foi reestruturado para se adequar aos propósitos da pesquisa "Elites políticas parlamentares municipais da Grande Vitória (ES)". O questionário contém questões fechadas e abertas, que possibilitaram mobilizar variáveis quantitativas e qualitativas para a apreensão das características dos perfis de carreira e das percepções políticas dos legisladores municipais.

O formulário foi dividido em três blocos: (a) perfil social e trajetória partidária, (b) hábitos de mídia e (c) valores da democracia. No bloco de perfil social e trajetória partidária foram apreendidas as seguintes informações: idade, gênero, cor, igreja (religião), escolaridade, ocupação profissional, ano de filiação, partido atual, ocupação de cargos em órgãos estratégicos (eletivos ou não), principal cargo para carreira política, número de eleições disputadas, principais fontes de financiamento, principais apoios na eleição, se recebeu apoio de algum deputado estadual ou federal, base eleitoral, posição na escala ideológica, etc. Já no bloco hábitos de mídia foi coletada a frequência na utilização de certas mídias, tais como TV (por assinatura ou canal aberto), jornal impresso, rádio e acesso à internet. No bloco valores da democracia foram apreendidas as seguintes informações: concepção sobre os aspectos gerais da democracia, avaliação dos obstáculos para o desenvolvimento da democracia, consolidação da democracia no Brasil, etc.

As quatro Câmaras Municipais contabilizam um total de 74 vereadores (Vitória: 1512, Vila Velha: 17-13, Serra: 23-20 e Cariacica: $\left.19-13^{4}\right)$. A aplicação do questionário atingiu 58 parlamentares, que compõem a amostra da pesquisa ${ }^{5}$. Os dados coletados passaram primeiramente por uma análise de consistência, depois foram codificados e

\footnotetext{
${ }^{3}$ A Região Metropolitana da Grande Vitória é constituída pelos seguintes municípios: Vitória, Vila Velha, Serra, Cariacica, Fundão, Guaraparí e Viana. Dentre eles Vitória, Vila Velha, Serra e Cariacica são os municípios que se destacam na região metropolitana, juntos representam $55,0 \%$ da população e $70,0 \%$ do PIB do Estado.

${ }^{4} \mathrm{O}$ primeiro número é o total de vereadores da Câmara Municipal, já o segundo é o total de entrevistados.

${ }^{5} \mathrm{O}$ propósito era entrevistar todos os vereadores dos municípios citados, mas alguns vereadores não puderam ou não quiseram participar.
} 
inseridos em planilha computacional. Para o gerenciamento e a análise do banco de dados foi utilizado o software Sphinx.

\subsection{Dimensão II: Atributos adscritos e adquiridos dos vereadores}

Os atributos adscritos dizem respeito a algumas características sociais que diferem e definem as pessoas, por exemplo: gênero, idade, cor da pele, cor dos olhos, etc. Por outro lado, os atributos adquiridos tem relação com as conquistas ou valoração que marcam a trajetória de vida das pessoas, por exemplo, religião, grau de instrução, ocupação, estado civil, etc (KELLER, 1967).

Com relação aos atributos adscritos, a Tabela 1 mostra a distribuição do gênero, faixa etária e cor da pele.

\section{Tabela 1 \\ Distribuição do gênero, faixa etária e cor da pele \\ Grande Vitória (ES), 2015}

\begin{tabular}{lc}
\hline Gênero, faixa etária, cor da pele & $\%$ \\
\hline Gênero & \\
Homem & 94,8 \\
Mulher & 5,2 \\
TOTAL & $\mathbf{1 0 0 , 0}$ \\
& \\
Faixa etária & \\
Até 29 anos & 3,4 \\
De 30 a 39 anos & 10,3 \\
De 40 a 49 anos & 31,1 \\
De 50 a 59 anos & 44,9 \\
De 60 a 69 anos & 8,6 \\
70 anos ou mais & 1,7 \\
TOTAL & $\mathbf{1 0 0 , 0}$ \\
& \\
Cor da pele & \\
Branca & 52,0 \\
Negra & 13,8 \\
Parda/Morena & 32,5 \\
Amarela & $-{ }^{*}$ \\
NS ${ }^{\star *}$ & 1,7 \\
TOTAL & $\mathbf{1 0 0 , 0}$ \\
\hline Fonte: Elaboração própria a partir da pesquisa do NPSA/UVV. \\
Nota: * Sinal para indicar \% igual à zero. ${ }^{* *}$ Abreviação para indicar \\
"Não sei”.
\end{tabular}


A ex-deputada federal Denise Frossard (PPS/RJ) ao comentar a situação da relação de gênero na política brasileira, sobretudo no interior do poder Legislativo, disse que a Câmara dos Deputados "[...] é uma casa de machos" (VIANNA, 2005, p. 1). A afirmação não é novidade nas análises sociológicas sobre a relação de gênero na política. O mundo da política ainda é muito masculino e acreditamos que isto se agrava ainda mais na política municipal.

Da matriz de dados acima vemos que nas quatro Câmaras Municipais analisadas, 94,8\% são homens, enquanto somente 5,2\% são mulheres. Quando olhamos para Assembleia Legislativa do Estado do Espírito Santo também vemos um predomínio dos homens no interior dessa casa, com $86,7 \%$ de um total de 30 parlamentares. Nas últimas legislaturas da Câmara dos Deputados o cenário se repete: apenas cerca de 10,0\% são mulheres (ARAUJO, 2013). Tal descoberta também foi apreendida por outras pesquisas que buscaram identificar os atributos adscritos no interior dos municípios. Kerbauy (2014), ao analisar os dados da pesquisa "Organização e funcionamento da política representativa no Estado de São Paulo (1994-2014)", identificou uma grande desproporção na relação de gênero: de uma amostra de 400 vereadores, 89,9\% são homens e só 10,1\% são mulheres. Ainda segundo a autora:

As Câmaras Municipais brasileiras continuam sendo majoritariamente masculinas. Os dados sobre a composição do legislativo local apresentam, desde 1997, um percentual muito baixo de participação feminina. Mesmo depois da Lei n. 9.504, em vigor desde 1996, a cota de 30,0\% de candidatas exigidas pela lei nunca foi cumprida integralmente pelos partidos. Nas eleições de 2012, a Justiça Eleitoral cobrou a obrigatoriedade do mecanismo de cotas, provocando o aumento para $32,6 \%$ do número de candidatas mulheres. Contudo, o número de candidatas eleitas nestas eleições foi de 13,3\% (7.635 vereadoras) (KERBAUY, 2014, p. 6).

Embora a Lei n. 9.504 tente amenizar o problema da participação das mulheres nas competições eleitorais, a presença delas ainda é muito baixa. Acreditamos que as atividades laborais das mulheres e a percepção que a sociedade tem delas na vida pública, em que o machismo prevalece nas relações de poder, comprometem 0 estreitamento com os partidos e sabemos que a participação em posições de poder no interior das legendas é crucial para uma maior competitividade nas disputas políticas. Se o nível de integração da mulher no partido é baixo, consequentemente diminuem as chances do sexo feminino de se eleger para qualquer cargo legislativo no interior dos 
municípios. Essas constatações indicam a reprodução de um ambiente em que sobressaem os homens na arena legislativa.

O exame da distribuição por faixa etária, conforme mostrado na Tabela 1, demonstra que $44,9 \%$ estão na faixa dos 50 a 59 anos, 31,1\% pertencem ao grupo dos 40 a 49 anos, 10,3\% estão na faixa dos 30 a 39 anos e 13,7\% pertencem aos outros grupos etários (até 29 anos, 60 a 69 anos e 70 anos ou acima). Os percentuais apontam que a elite local da Grande Vitória é relativamente envelhecida, ou seja, 76,0\% dos vereadores entrevistados possuem idade entre 40 a 59 anos. Diferentemente, na pesquisa com os 400 parlamentares municipais do Estado de São Paulo, Kerbauy (2014, p. 6) identificou um crescimento no seio do grupo de 30 a 39 anos, indicando, segundo a autora, "[...] o rejuvenescimento deste segmento da classe política".

O último dado referente aos atributos adscritos diz respeito à cor da pele. Dos 56 entrevistados, 52,0\% afirmaram que a cor é branca, 32,5\% declararam parda/morena e somente 13,8\% afirmaram que a cor é preta. Vemos uma dominância da cor branca no interior da nossa amostra sobre a elite parlamentar local. Essa constatação também é ressaltada por Kerbauy com os vereadores do Estado de São Paulo: "Em relação à raça/cor, o maior percentual dos vereadores se declarou branco 60,0\%, seguido por $30,7 \%$ de pardo ou moreno e, 5,8\%, preto" (KERBAUY, 2014, p. 7). Aqui ou lá, os brancos dominam a política municipal.

Com relação aos atributos adquiridos, a Tabela 2 mostra a distribuição do grau instrução, ocupação profissional e filiação religiosa (igreja).

\section{Tabela 2 \\ Distribuição do grau de instrução, ocupação profissional e igreja Grande Vitória (ES), 2015}

Grau de instrução, ocupação profissional e igreja $\quad \%$

\begin{tabular}{lc}
\hline Grau de instrução & \\
Até o Ensino fundamental & 3,4 \\
Até o Ensino médio completo & 51,6 \\
Graduação completa & 25,8 \\
Especialização/Mestrado/Doutorado & 17,5 \\
NR* & 1,7 \\
TOTAL & 100,0 \\
& \\
Ocupação profissional & \\
Empregados públicos & 31,0 \\
Comerciantes & 10,5 \\
Professores & 5,2
\end{tabular}


Profissionais liberais $\quad 11,8$

Comunicadores $\quad 3,6$

Empresarial $\quad 5,2$

Políticos profissionais $\quad 3,5$

Empregados manuais $\quad 17,2$

Sindicalistas $\quad 1,7$

Trabalhadores agrícolas $\quad 1,7$

Pastores $\quad 1,7$

Trabalhadores segurança pública $\quad 1,7$

Outras profissões $\quad 5,2$

$\begin{array}{lc}\text { TOTAL } & 100,0\end{array}$

Filiação religiosa (Igreja)
Católica
52,0

Batista 12,8

Assembleia de Deus $\quad 11,1$

Quadrangular $\quad 5,7$

Adventista $\quad 1,9$

Outras igrejas $\quad 10,9$

$\mathrm{NR}^{*} \quad 5,6$

TOTAL 100,0

Fonte: Elaboração própria a partir da pesquisa do NPSA/UVV.

Nota: * Abreviação para indicar "Não respondeu".

Ao olharmos para a escolaridade dos vereadores capixabas, observamos que $51,6 \%$ possuem até o ensino médio/graduação incompleta. Por outro lado, 25,8\% afirmaram ter graduação completa e $17,5 \%$ possuem algum(a) especialização/mestrado/doutorado. Quando comparado com os dados de Kerbauy (2014), dos 400 vereadores entrevistados, 28,7\% afirmaram ter graduação completa e $25,8 \%$ declararam possuir o ensino médio completo. Na outra ponta, 9,4\% são pósgraduados e $8,4 \%$ têm somente o ensino fundamental.

Os vereadores capixabas são funcionários públicos, empregados manuais, profissionais liberais e comerciantes, com, respectivamente, 31,0\%, 17,2\%, 11,8\% e $10,5 \%$ do total. As repartições públicas (empregados públicos) continuam sendo o principal celeiro de recrutamento para candidatos ao cargo de vereança. Também não podemos deixar de ressaltar que as ocupações profissionais ligadas aos empregos manuais, aos ditos profissionais liberais e os comerciantes também são fontes que alimentam o processo de seleção da classe política local da Grande Vitória. Em resumo, podemos dizer que são ocupações da profissão política. A matriz de dados ainda informa que $3,5 \%$ dos entrevistados declararam que são políticos profissionais.

O último dado referente aos atributos adquiridos diz respeito à religião, que é representado pela variável igreja a que pertence. Vemos que a tabela deixa claro que os vereadores entrevistados pertencem à religião católica e evangélica, com 52,0\% e 31,5\% 
do total, respectivamente. O predomínio do católico também foi identificado na pesquisa com os legisladores do Estado de São Paulo, com 73,9\% (KERBAUY, 2014). Tal constatação não nos surpreende, pois o Brasil é uma das maiores nações católicas do mundo. Segundo o IBGE, com o Censo de 2010, 64,6\% dos brasileiros declararam católicos. Assim, a igreja católica e também as igrejas evangélicas são, de longe, os principais celeiros de abastecimento da classe política local.

\subsection{Dimensão III: Perfis de carreira e partidário dos parlamentares}

Os perfis de carreira e partidário são relevantes para os estudos de recrutamento dos membros da classe política parlamentar, pois é por meio de algumas variáveis que vamos identificar como esses integrantes estão distribuídos sociologicamente no interior dessa classe. Ademais, possibilita saber como eles adquiriram o "[...] status de representante do povo e do vocativo de Vossa Excelência" (RODRIGUES, 2006, p. 65).

Para isto, iniciamos a nossa análise dos perfis de carreira e partidário com uma pergunta feita aos entrevistados: Em que momento da sua vida você teve contato pela primeira vez com a política? Como foi uma pergunta do tipo aberta e espontânea tivemos um grande número de respostas, que permitiu conhecer os momentos e as circunstâncias em que os vereadores se aproximaram da política. Os principais momentos citados foram: chefe de unidade de saúde do bairro, com a eleição do Vitor Buaiz para prefeito de Vitória, comunidade eclesial de base, contato com a carência do bairro, Diretas Já!, familiares, grupos de jovens na igreja, incentivo de colegas da igreja, juventude, liderança no bairro/líder comunitário, movimento estudantil, mãe líder comunitária em Vitória, participação na igreja/pastorais, quando Lula foi eleito, socorrendo/ajudando pessoas, etc. Muitos também indicaram o ano em que entraram em contato com a política: 1970, 1980, 1982, 1994, 1996, 1997, 2002 e 2007. Liderança no bairro/líder comunitário foi o mais citado por eles, mas o que chamou a atenção foram as menções à igreja, que, tudo indica, é uma fonte que alimenta as elites políticas locais. Estar vinculado a igreja aumenta as chances de sair como candidato e até de vencer as eleições. Não podemos deixar de dizer que ser liderança no bairro/líder comunitário é uma das atividades que contribui para a autopromoção pessoal, pois assim se pode conquistar o capital político 
necessário para construir uma candidatura e até mesmo para ganhar as disputas eleitorais.

Embora eles tenham revelado momentos que contribuíram para o despertar político, quando olhamos para o ano de filiação observamos que mais de $70,0 \%$ dos entrevistados se filiou a um partido nos anos de 2003, 2004, 2005, 2007, 2008, 2011, 2012 e 2013, enquanto os demais parlamentares se associaram a uma legenda nos anos de 1977, 1985, 1986, 1990 e 1997. A Tabela 3 mostra o ano de filiação ao atual partido.

\section{Tabela 3 \\ Ano de filiação ao atual partido Grande Vitória (ES), 2015}

\begin{tabular}{lc}
\hline Ano de filiação & $\%$ \\
\hline 1977 & 4,8 \\
1985 e 1986 & 9,6 \\
1990 e 1997 & 14,2 \\
$2003,2004,2005,2007$ e 2008 & 33,3 \\
2011, 2012 e 2013 & 38,1 \\
TOTAL & $\mathbf{1 0 0 , 0}$ \\
\hline Fonte: Elaboração própria a partir da pesquisa do \\
NPSA/UVV.
\end{tabular}

O que chamou a nossa atenção na matriz acima foi o número de filiações recentes dos vereadores no atual partido, $38,1 \%$ dos parlamentares se filiaram no período compreendido de 2011 a 2013. Kerbauy (2014) também identificou o mesmo fenômeno: mais da metade dos 400 entrevistados se filiou entre 2000 e 2014. A nossa pesquisa e a de Kerbauy (2014) não permitem identificar se essas associações dizem respeito à primeira filiação dos vereadores ou se eles desfiliaram para filiar a outra legenda. Se for a primeira filiação esse fato aponta para uma renovação da classe política parlamentar municipal. Todavia, acreditamos que, para disputar as eleições de 2012, a maioria dos $38,1 \%$ se desfiliou de uma sigla para se associar a outra. Os dados da Tabela 3 ainda revelam que $47,8 \%$ dos entrevistados são leais aos seus partidos. Isto significa que eles estão há 10 ou mais anos (1977, 1985, 1986, 1990, 1997, 2003, 2004 e 2005) no mesmo partido. Braga, Leine e Sabbag (2015), utilizando os dados da pesquisa "Organização e funcionamento da política representativa no Estado de São Paulo (1994-2014)”, também identificaram essa lealdade para $27,0 \%$ dos entrevistados. 
Quando olhamos a lista dos partidos filiados podemos ver que os 58 entrevistados estão espalhados por 15 legendas: PT com 19,0\%, PPS, PSB e PTN com 9,4\% cada sigla e PCdoB, PSDB, PRP, PRB, PMDB, PHS, PMN, Solidariedade, PR, PTdoB e PP com $4,8 \%$ cada partido. Seguindo Silva e Silva (2015), esses partidos perpassam todo 0 continuum ideológico e podem ser distribuídos em três blocos: i) esquerda: PT, PPS, PSB e PCdoB, ii) centro: PMDB e PSDB e iii) direita: PTN, PRP, PRB, PHS, PMN, Solidariedade, PR, PTdoB e PP.

Sabemos que ocupar cargos eletivos e não-eletivos em órgãos estratégicos é a porta de entrada para a classe política. Ao ocupar esses postos, os políticos conhecem a natureza do poder adquirindo e a capacidade de negociar e manter relações com os demais envolvidos no jogo político. A Tabela 4 sintetiza os cargos ocupados pelos vereadores.

\section{Tabela 4}

Cargos ocupados em órgãos estratégicos

Grande Vitória (ES), 2015

\begin{tabular}{|c|c|c|c|c|}
\hline Órgãos & Ocupou & Ocupa & $\begin{array}{l}\text { Não } \\
\text { ocupa }\end{array}$ & TOTAL \\
\hline Diretório Partidário Nacional & 5,2 & 3,5 & 91,3 & 100,0 \\
\hline Diretório Partidário Estadual & 15,5 & 20,7 & 63,8 & 100,0 \\
\hline Diretório Partidário Municipal & 22,4 & 60,3 & 17,3 & 100,0 \\
\hline Diretório Partidário Regional & 8,6 & 15,5 & 75,9 & 100,0 \\
\hline $\begin{array}{l}\text { Secretaria ou Subsecretaria } \\
\text { Municipal }\end{array}$ & 20,7 & 1,7 & 77,6 & 100,0 \\
\hline $\begin{array}{l}\text { Secretaria ou Subsecretaria } \\
\text { Estadual }\end{array}$ & 1,7 & -* & 98,3 & 100,0 \\
\hline Ministério Governo Federal & - & 1,7 & 98,3 & 100,0 \\
\hline $\begin{array}{l}\text { Direção de Organização não } \\
\text { Governamental }\end{array}$ & 22,4 & 3,5 & 74,1 & 100,0 \\
\hline $\begin{array}{l}\text { Direção de Associação de } \\
\text { Bairro }\end{array}$ & 56,9 & 1,7 & 41,4 & 100,0 \\
\hline $\begin{array}{l}\text { Direção de Sindicato } \\
\text { Direcão de Associacão }\end{array}$ & 15,5 & 3,5 & 81,0 & 100,0 \\
\hline $\begin{array}{l}\text { Recreativa } \\
\text { Direção de Organização }\end{array}$ & 6,9 & 8,6 & 84,5 & 100,0 \\
\hline $\begin{array}{l}\text { Estadual } \\
\text { Direção de Associação }\end{array}$ & 19,0 & 1,7 & 79,3 & 100,0 \\
\hline Empresarial & 6,9 & 1,7 & 91,4 & 100,0 \\
\hline $\begin{array}{l}\text { Direção de Associação } \\
\text { Religiosa }\end{array}$ & 22,4 & 8,6 & 69,0 & 100,0 \\
\hline
\end{tabular}

Fonte: Elaboração própria a partir da pesquisa do NPSA/UVV.

Nota: * Sinal para indicar \% igual à zero. 
O destaque da tabela está na primeira coluna, pois aí podemos perceber que boa parte dos entrevistados ocupou algum cargo, seja ele eletivo ou não-eletivo. É de 56,9\%a taxa dos vereadores vinculados à Direção de Associação de Bairro. Tal vínculo pode indicar que muitos começaram no interior das Associações de Bairros, adquiram o capital necessário e saíram candidatos a vereança. Também devemos destacar que muitos estavam vinculados aos Diretórios Partidários Municipais, as Direções de Organizações não Governamentais, às Direções de Associações Religiosas, às Secretarias ou Subsecretarias Municipais, às Direções de Organizações Estaduais, às Direções Sindicais e aos Diretórios Partidários estaduais com, respectivamente, 22,4\%, 22,4\%, 22,4\%, $20,7 \%, 19,0 \% 15,5 \%$ e $15,5 \%$ do total. Todos esses órgãos são fontes primárias de recrutamento da classe política capixaba, mas são poucos que conseguem perfurar a casca dura que protege essa classe.

Ainda olhando para matriz de dados, podemos notar que muitos dos nossos entrevistados ainda ocupam cargos em todos os órgãos, com destaque especial para os Diretórios Partidários Municipais. Por outro lado, muitos não ocuparam postos em nenhum desses órgãos. O que foi constatado com os dados apresentados na Tabela 4 também foi identificado pela pesquisa de Kerbauy (2004).

Os nossos parlamentares não são "marinheiros de primeira viagem" nas disputas eleitorais, eles são políticos que disputaram muitos pleitos. Ademais muitos deles sonham com altos cargos ao longo das suas carreiras eletivas. A Tabela 5 mostra a quantidade de eleições disputadas e de postos desejados.

\section{Tabela 5 \\ Eleições disputadas e cargos desejados Grande Vitória (ES), 2015}

\begin{tabular}{lc}
\hline $\begin{array}{l}\text { Eleições disputadas e cargos } \\
\text { desejados }\end{array}$ & $\%$ \\
\hline Eleições disputadas & \\
Uma eleição & 5,2 \\
Duas eleições & 24,2 \\
Três eleições & 27,6 \\
Quatro eleições & 15,5 \\
Cinco eleições & 10,3 \\
Seis eleições & 8,6 \\
Sete eleições ou mais & 8,6 \\
TOTAL & $\mathbf{1 0 0 , 0}$ \\
& \\
Cargos almejados & \\
Vereador & 29,3
\end{tabular}




\begin{tabular}{lc} 
Prefeito & 15,5 \\
Deputado Estadual & 32,9 \\
Deputado Federal & 10,3 \\
Governador & 5,2 \\
Senador & 1,7 \\
Presidente da República & $-{ }^{*}$ \\
NS/NR ${ }^{\star *}$ & 5,1 \\
TOTAL & $\mathbf{1 0 0 , 0}$ \\
\hline Fonte: Elaboração própria a partir da pesquisa do \\
NPSA/UVV. \\
Nota: * Sinal para indicar \% igual à zero. ** \\
$\begin{array}{l}\text { Abreviações } \\
\text { sabe" e "Não respondeu". }\end{array}$
\end{tabular}

Eles não são iniciantes nas disputas eleitorais. A matriz de dados acima deixa evidente que os entrevistados já competiram em vários pleitos, dando a eles o capital político necessário para conhecerem as artimanhas das disputas eleitorais. Outra informação que podemos retirar da quantidade das eleições disputadas é que os entrevistados devem possuir algum tipo de perfil que é priorizado nas listas partidárias, assim, eles sempre ocuparão as preferências indicativas dos partidos para participarem das disputas eleitorais na esfera municipal. Com isto eles estão constantemente lutando para permanecer no diminuto grupo político local.

Dos vereadores entrevistados, 98,3\% pretendem prosseguir na carreira política depois do fim do atual mandato (2013-2016). Muitos deles sonham alto na carreira política $(65,6 \%)$, enquanto alguns $(29,3 \%)$ pretendem permanecer no cargo de vereança. Para esses que têm ambição progressiva e sonham, o posto de deputado estadual é o mais desejado por eles, com 32,9\%, ao passo que os cargos de prefeito, deputado federal, governador e senador, com, respectivamente, 15,5\%, 10,3\%, 5,2\% e 1,7\%, do total, são postos secundários almejados pelos entrevistados. Se eles sonham alto, no pleito de 2012, quais foram as principais fontes de financiamento de suas campanhas? Quais foram os principais apoios que receberam? Quais foram suas bases eleitorais?

Seja no âmbito nacional ou subnacional, qualquer disputa eleitoral é muito cara para o bolso do candidato. Para Samuels (2006), as eleições no Brasil são caras e segundo ele alguns fatores contribuem para isto: i) as eleições legislativas geram altos custos com as campanhas, ii) a competição aumenta significativamente entre os candidatos, que precisam gastar muito com as campanhas e iii) os partidos são fracos na arena eleitoral $\mathrm{e}$ isto força os candidatos a buscarem recursos financeiros fora da estrutura partidária. Os fatores acima deixam as competições eleitorais mais caras e aqueles que não contam com próprio financiamento ou têm dificuldades na obtenção de 
recursos financeiros são prejudicados na corrida por uma cadeira da casa Legislativa (SAMUELS, 2006).

Na disputa eleitoral de 2012, os entrevistados informaram que contaram com várias fontes de financiamento (desde doações de empresas a uso de recursos próprios) para promover suas campanhas. A Tabela 6 discrimina as diversas fontes, mas também destaca os apoios recebidos e as bases eleitorais.

\section{Tabela 6 \\ Fontes de financiamento, apoios \\ recebidos e bases eleitorais \\ Grande Vitória (ES), 2015}

\begin{tabular}{lc}
\hline Fontes, apoios e bases & $\%$ \\
\hline Fontes de financiamento & \\
Doações de empresas & 10,4 \\
Recursos do partido ou & 24,1 \\
coligação & 25,9 \\
Doações de pessoas físicas & 62,1 \\
Recursos próprios & $\mathbf{1 2 2 , 5 ^ { \star }}$ \\
TOTAL &
\end{tabular}

\section{Apoios recebidos}

Familiar

Líderes ou grupos religiosos

Líderes comunitários ou

sindicais

Partidário

8,6

Candidato a prefeito

6,9

Prefeito em exercício

5,2

Líderes empresariais

Deputados da região

1,7

Não teve apoio de pessoas ou grupos

-**

10,3

TOTAL

$175,9^{\star \star *}$

\section{Bases eleitorais}

Moradores de um determinado bairro/região do município

Grupos religiosos

Movimentos sociais

Associações profissionais

TOTAL

Fonte: Elaboração própria a partir da pesquisa do NPSA/UVV.

Nota: * O valor percentual de 122,5 significa que alguns vereadores consideraram mais de uma fonte como principal. ** Sinal para indicar \% igual à zero. *** O valor percentual de 175,9 significa que alguns vereadores consideraram mais de um apoio como principal. ${ }^{* * *} \mathrm{O}$ valor percentual de 172,4 significa que 
O primeiro conjunto de dados (fontes de financiamento) acima converge com o terceiro fator destacado por Samuels (2006), que é: os partidos são fracos na arena eleitoral de modo a forçar os candidatos a buscarem recursos financeiros fora da estrutura partidária. Nesse caso, muitos deles contaram com eles mesmos $(62,1 \%)$ e com as colaborações de outros financiadores: doações de pessoas físicas $(25,9 \%)$ e de empresas $(10,4 \%)$. Quando comparado com o montante, os recursos oriundos dos partidos ou coligações são poucos (24,1\%). Com o segundo conjunto de dados (apoios recebidos), exposto na Tabela 6 , vê-se que somente $8,6 \%$ receberam suporte dos seus respectivos partidos e isto reforça ainda mais a baixa colaboração financeira oferecida pelas siglas partidárias. Kerbauy também identificou esse fenômeno com os vereadores paulistas:

[...] a principal fonte de financiamento, 68,2\% (272 vereadores) responderam que são recursos próprios, apontando para a fragilidade de recursos financeiros dos diretórios partidários locais ou de suas comissões provisórias. Nesse sentido suas bases eleitorais são importantes, pois com poucos recursos a campanha depende dos vínculos estabelecidos com a sociedade civil (KERBAUY, 2014, p. 14).

Quando atentamos para o segundo conjunto de dados, temos um panorama dos apoios recebidos pelos vereadores ao longo do pleito de 2012, que, por sua vez, contribuíram para vitória eleitoral. Vimos que o partido ofereceu baixo apoio, todavia, os parlamentares tiveram um alto apoio familiar (62,1\%), acompanhado dos apoios de lideranças/grupos religiosos (41,4\%) e lideranças comunitárias/sindicais $(39,7 \%)$. Por outro lado, os vereadores receberam pouquíssimo apoio de políticos, sejam eles de candidatos ao poder Executivo, de prefeitos em exercício ou de deputados da região. Quando foi perguntado se os vereadores receberam apoio de algum deputado estadual ou federal nas eleições de 2012, 70,7\% responderam que 'não'.

A matriz de dados fornece também informações sobre as bases eleitorais dos vereadores e mostra que $75,9 \%$ deles se concentraram espacialmente em um determinado bairro do município. Por outro lado, os grupos religiosos, os movimentos sociais e as associações profissionais também constituíram bases eleitorais dos parlamentares, com, respectivamente, $46,5 \%, 27,6 \%$ e $22,4 \%$ do total.

Se o sonho de muitos é ocupar altos cargos eletivos (deputado estadual, prefeito, deputado federal, governador e senador) eles precisarão trabalhar muito, pois a situação 
descrita acima ajuda muito pouco para um sucesso eleitoral em postos eletivos de mais alto escalão. Isto significa que eles terão que buscar mais financiamento para suas campanhas e estreitar ainda mais os laços com outros membros da elite local para aumentar as suas bases eleitorais.

\subsection{Dimensão IV: Percepções políticas dos vereadores}

A América Latina passou, desde o final da década de 1970, por um processo generalizado de mudança de regimes políticos, dentro daquilo que foi chamado por Huntington (1994) de terceira onda de democratização. Nesse cenário de transformação, alguns países (por exemplo, Brasil, Argentina, Uruguai, Paraguai e Chile) fizeram a transição saindo do autoritarismo para o regime democrático. Observando o caso brasileiro, em 01 de fevereiro de 2019 a nossa democracia completou 32 anos $^{6}$ e é a mais longeva experiência democrática. Estudos de José Álvaro Moisés (2010) e do Latinobarómetro indicam que a democracia brasileira está movendo pedras para continuar sua caminhada democratizante. Com relação a isto, em pesquisa realizada pelo Núcleo de Pesquisa Social Aplicada a respeito das opiniões da população na Grande Vitória (ES) apreendemos que a democracia é bem avaliada para 57,5\% dos entrevistados, sendo que a democracia é sempre melhor.

Se para população entrevistada a democracia é sempre melhor, o que pensam os parlamentares municipais? Todavia, antes de respondermos esta pergunta convém saber como os entrevistados definiram a democracia. Para isto, abrimos o Bloco 3 do questionário (Valores da democracia) com a questão aberta: Defina democracia numa palavra. Para eles, a democracia é: cidadania, cooperação, ética, igualdade, liberdade, participação, povo e respeito. Estas palavras nos levam a pensar que os vereadores entrevistados percebem a democracia como sendo um regime com um viés mais participativo, em que a cidadania, cooperação, ética, igualdade, liberdade, participação, povo e respeito são palavras que balizam esse regime. Conhecida a percepção de democracia dos vereadores, a Tabela 7 exibe os percentuais dos entrevistados sobre 0 apoio ao regime democrático.

\footnotetext{
${ }^{6}$ Datamos a nossa democracia com a instalação da Assembleia Nacional Constituinte, que ocorreu no dia primeiro de fevereiro de 1987 (ABRANCHES, 2001).
} 


\section{Tabela 7 \\ Apoio à democracia \\ Grande Vitória (ES), 2015}

\begin{tabular}{|c|c|}
\hline Apoio à democracia & $\%$ \\
\hline $\begin{array}{l}\text { A democracia é preferível a } \\
\text { qualquer outra forma de } \\
\text { governo. }\end{array}$ & 82,7 \\
\hline $\begin{array}{l}\text { Em algumas circunstâncias, um } \\
\text { governo autoritário pode ser a } \\
\text { melhor escolha. }\end{array}$ & 5,2 \\
\hline $\begin{array}{l}\text { Um governo autoritário é mais } \\
\text { eficaz que um governo } \\
\text { democrático. }\end{array}$ & $-*$ \\
\hline $\begin{array}{l}N^{\star \star *} \\
\text { TOTAL }\end{array}$ & $\begin{array}{c}12,1 \\
\mathbf{1 0 0 , 0}\end{array}$ \\
\hline $\begin{array}{l}\text { Fonte: Elaboração própria a partir da } \\
\text { NPSA/UVV. } \\
\text { Nota: * Sinal para indicar \% igual à zero. } \\
\text { para indicar "Não respondeu". }\end{array}$ & $\begin{array}{l}\text { esquisa do } \\
\text { Abreviação }\end{array}$ \\
\hline
\end{tabular}

A Tabela 7 nos diz que para $82,7 \%$ dos entrevistados a democracia é preferível a qualquer outra forma de governo, deixando a entender que para eles a democracia é sempre melhor. Tal constatação também foi apreendida por outras pesquisas que buscaram identificar o apoio da elite local à democracia. Felisbino e Kerbauy (2012) ao analisarem as percepções dos vereadores de São Bernardo do Campo, Santo André e São Caetano do Sul, Estado de São Paulo, apreenderam que para 95,3\% a democracia é sempre a melhor forma de governo. Com base nas informações da Tabela 7, podemos dizer que para os vereadores da Grande Vitória a volta ao autoritarismo está longe de ser preferida à democracia. Além disso, a tabela ainda informa que somente 5,2\% creem que, em algumas circunstâncias, um governo autoritário pode ser a melhor escolha para momentos de crises.

Se o apoio à democracia é alto entre os vereadores entrevistados, seria interessante saber sobre a estabilidade do regime democrático. Para identificar essa estabilidade, trabalhamos com algumas categorias como muito e bastante estável e acreditamos que a diferença entre elas está na intensidade que cada palavra nós transmite. No Dicionário de Língua Portuguesa Houaiss (2009) encontramos essas distinções: o termo Muito (advérbio) significa exageradamente, excessivamente, ou, ainda, abundantemente; enquanto o termo Bastante (também advérbio) expressa 
quantidade suficiente, satisfatoriamente, ou, ainda, muito de maneira acima da média. A categoria muito estável agrega mais intensidade que a categoria bastante estável, pois muito é mais forte que bastante. Embora exista a diferença de intensidade, o importante é saber se os entrevistados reconhecem se atualmente a democracia no Brasil está muito ou bastante estável, pois ambas as opiniões demonstram que o regime democrático está em um processo contínuo de democratização e não o seu reverso, a desdemocratização (TILLY, 2013). A Tabela 8 nos mostra a estabilidade.

\section{Tabela 8 \\ Estabilidade da democracia Grande Vitória (ES), 2015}

\begin{tabular}{lc}
\hline Estabilidade & $\%$ \\
\hline Muito estável & 24,4 \\
Bastante estável & 41,3 \\
Pouco estável & 25,8 \\
Não é estável & 8,5 \\
TOTAL & $\mathbf{1 0 0 , 0}$ \\
\hline Fonte: Elaboração própria a partir da pesquisa do \\
NPSA/UVV.
\end{tabular}

$\mathrm{Na}$ tabela acima podemos ver que a maioria dos parlamentares pensa que a democracia está bastante estável, por outro lado 24,4\% afirmaram que ela está muito estável. Ao somarmos as categorias muito e bastante estável temos um parâmetro do quanto os parlamentares estão otimistas ou não em avaliar a estabilidade do regime democrático. Para $65,7 \%$ dos vereadores entrevistados a democracia está estável, enquanto $34,3 \%$ não estão otimistas com a estabilidade do regime democrático. Acreditamos que para esses vereadores que não estão otimistas (34,3\%), a crise política e econômica, que iniciou no final de 2014 e prosseguiu ao longo de 2015, afetou as opiniões dos entrevistados com relação à estabilidade democrática.

Vimos que os vereadores capixabas apoiam a democracia, no entanto não sabemos a forma desse apoio. Para identificarmos essa forma, um dos meios que utilizamos foi apresentar aos entrevistados algumas afirmações que perpassam pelo tema da participação política, pois é um assunto, juntamente com a representação, que baliza o conceito de democracia contemporânea. O que se busca é conhecer as opiniões dos vereadores sobre as medidas que visem fortalecer o alargamento das esferas de 
participação dos cidadãos no interior da sociedade. A Tabela 9 exibe os percentuais dos entrevistados sobre algumas formas de participação.

\section{Tabela 9 \\ Formas de participação \\ Grande Vitória (ES), 2015}

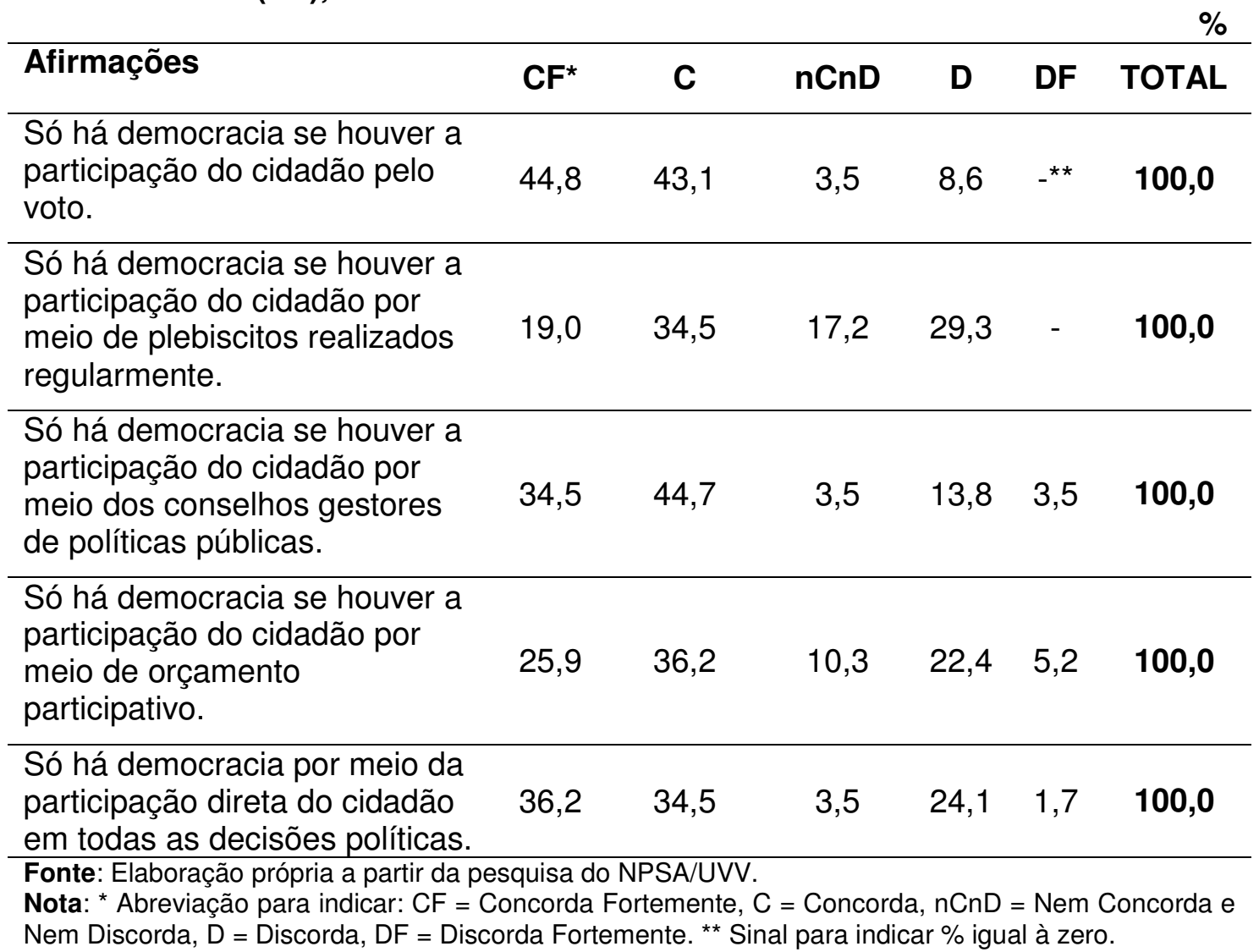

Podemos notar que para $87,9 \%^{7}$ dos parlamentares municipais entrevistados a democracia está fortemente vinculada ao campo eleitoral, ou seja, para eles só existe democracia se houver a participação do cidadão pelo voto. O percentual é bastante alto quando comparado com as outras formas de participação e isto nos leva a pensar que esta percepção converge com uma visão minimalista da democracia. Na outra ponta, uma visão mais participativa, aqui correspondente à participação direta do cidadão em todas as decisões, é bem aceita pela maioria dos vereadores, com 70,7\% - que concordam ou concordam fortemente. As demais formas possíveis de participação, como: conselhos gestores, orçamento participativo e plebiscito, com $79,2 \%, 62,1 \%$ e $53,5 \%$,

\footnotetext{
${ }^{7}$ Este percentual é a soma das categorias Concorda Fortemente e Concorda.
} 
respectivamente, são avaliadas satisfatoriamente, podendo ser utilizadas em parceria com a visão eleitoral.

Vimos nas matrizes acima que os vereadores capixabas dos municípios em análise aderem à democracia e suas opiniões refletem um viés participativo sobre esse regime, 0 que nos leva a pensar na seguinte questão: a opção ideológica influencia a percepção do vereador sobre a democracia? Vale dizer que em nossa pesquisa solicitamos ao entrevistado que se posicionasse numa escala de 1 a 10, na qual, para fins de análise, os valores 1, 2, 3 e 4 representam a esquerda, os valores 5 e 6 representam o centro e os valores 7, 8, 9 e 10 a direita. Abaixo está a representação gráfica da escala.

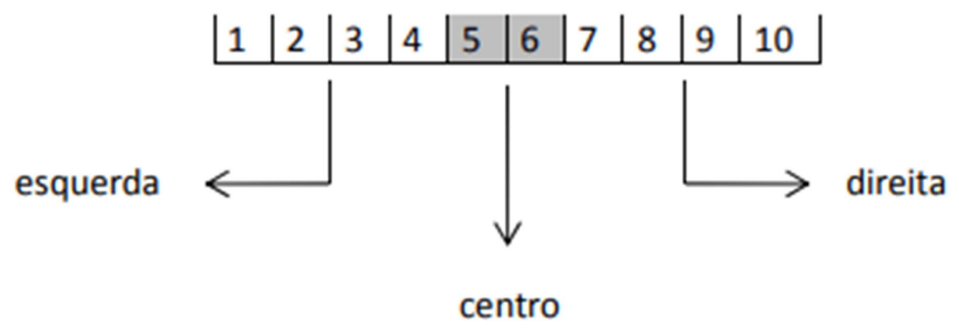

Este tipo de escala é uma técnica metodológica bastante utilizada na identificação da posição ideológica dos membros da classe política no continuum esquerda-direita. Todavia, para alguns estudiosos ela apresenta problemas:

[...] esse auto-posicionamento sofre de alguns limites metodológicos, sendo o principal deles o fato de o entrevistado poder não reconhecer o conteúdo dos termos utilizados (algo improvável quando se trata de pesquisa com elites políticas) ou simplesmente mentir sobre o seu posicionamento ideológico (PERISSINOTTO e BRAUNERT, 2007, p. 126).

Com relação ao primeiro fato ("não reconhecer o conteúdo dos termos utilizados"), assumimos que os respondentes têm uma ideia do que seja esquerda e direita. Partindo disto, os nossos entrevistados compreenderão a pergunta (Levando em conta as suas ideias políticas, onde o(a) Sr(a). se posiciona numa escala em que 1 indica a "esquerda" e 10 a "direita"?) e saberão se posicionar na escala apresentada a eles. Já com relação ao segundo fato ("simplesmente mentir sobre o seu posicionamento ideológico"), sabemos que isto pode ocorrer, pois com esta técnica para apreender a posição ideológica é impossível controlar esse problema de natureza pessoal. Ciente dos fatos, resolvemos utilizar a escala por ser um instrumento largamente usado no interior das Ciências Sociais e para não forçar o pesquisador a posicionar arbitrariamente os vereadores com base em sua filiação partidária. A Tabela 10 exibe a distribuição das posições. 


\section{Tabela 10 \\ Distribuição das posições na escala ideológica \\ Grande Vitória (ES), 2015}

$\%$

Escala

\begin{tabular}{c|c|c|c|c|c|c|c|c|c}
\hline \multicolumn{4}{c|}{ Esquerda } & \multicolumn{2}{c|}{ Centro } & \multicolumn{4}{c}{ Direita } \\
\hline 1 & 2 & 3 & 4 & 5 & 6 & 7 & 8 & 9 & 10 \\
\hline 13,8 & 1,7 & 6,9 & 3,5 & 25,9 & 10,3 & 10,3 & 6,9 & 1,7 & 13,8 \\
\hline \multicolumn{3}{c}{25,9} & \multicolumn{3}{c}{36,2} & \multicolumn{4}{c}{32,7} \\
\hline
\end{tabular}

Fonte: Elaboração própria a partir da pesquisa do NPSA/UVV.

Nota: $5,2 \%$ "Não respondeu".

De acordo com a nossa escala, que apresenta três grupos ideológicos (esquerda, centro e direita), podemos ver na matriz acima que o centro foi o espaço onde se encontra boa parte dos nossos entrevistados, com 36,2\%. Nesse espaço a posição 5 foi a escolha preferida deles, com 25,9\%. Por outro lado, a direita também foi o local de opção dos vereadores, com $32,7 \%$, enquanto o espaço da esquerda congregou $25,9 \%$ dos nossos entrevistados. Em "Quem é quem na constituinte", Leôncio Martins Rodrigues diz: "[...] ser (ou parecer) de esquerda [...] não é bom, mas pior ainda é ser (ou parecer) de direita" (RODRIGUES, 1987, p. 100). Seguindo o raciocínio do autor, podemos dizer que ser de centro (ou parecer) significa ter um posicionamento flexível que não entra em choque com quem é de esquerda ou de direita. Em suma, é conveniente estar no centro do jogo político.

Conhecido o lócus ideológico dos nossos entrevistados, seria interessante analisar as percepções dos vereadores que preferem a democracia a qualquer outro tipo de regime, segundo as suas escolhas ideológicas. A Tabela 11 apresenta o cruzamento entre democracia e opção ideológica. 


\section{Tabela 11 \\ Preferência pela democracia, segundo a opção ideológica Grande Vitória (ES), 2015}

$\%$

\begin{tabular}{lccc} 
Preferência pela & \multicolumn{3}{c}{ Opção ideológica } \\
\cline { 2 - 4 } democracia & Esquerda & Centro & Direita \\
\hline $\begin{array}{l}\text { A democracia é sempre a } \\
\text { melhor forma de governo. }\end{array}$ & 100,0 & 90,5 & 73,6 \\
\hline $\begin{array}{l}\text { A democracia às vezes é a } \\
\text { melhor forma de governo. }\end{array}$ & $-* *$ & 9,5 & 21,1 \\
\hline $\begin{array}{l}\text { A democracia nunca é a } \\
\text { melhor forma de governo. }\end{array}$ & - & - & - \\
\hline $\begin{array}{l}\text { É indiferente ter ou não } \\
\text { uma democracia. }\end{array}$ & - & - & 5,3 \\
\hline TOTAL & $\mathbf{1 0 0 , 0}$ & $\mathbf{1 0 0 , 0}$ & $\mathbf{1 0 0 , 0}$ \\
\hline
\end{tabular}

Fonte: Elaboração própria a partir da pesquisa do NPSA/UVV.

Na tabela acima temos três situações: i) na primeira situação, esquerda, centro e direita concentram a maioria dos nossos entrevistados, em que a democracia é sempre a melhor forma de governo, com, respectivamente, 100,0\%, 90,5\% e 73,6\% do total, ii) na segunda, centro e direita reúnem uma pequena parcela dos vereadores, em que a democracia às vezes é a melhor forma de governo, com, respectivamente, 9,5\% e 21,1\% do total e iii) na terceira situação, direita concentra uma parcela pequeníssima dos nossos entrevistados, em que é indiferente ter ou não democracia, com 5,3\% do total. O cruzamento das variáveis revela por ora que pode existir uma relação entre preferência pela democracia e opção ideológica: conforme se caminha da esquerda para a direita, o apoio incondicional à democracia vai decaindo, enquanto aumenta o percentual dos que acham que às vezes outras formas de governo são preferíveis à democracia.

Embora exista uma forte sintonia dos parlamentares com a democracia, eles ressaltaram que existem alguns fatores que podem ameaçar o regime democrático. A fim de identificar esses fatores apresentamos a eles uma lista com nove situações que estão presentes na própria estrutura sociopolítica brasileira, e que poderiam ameaçar a democracia. A Tabela 12 exibe os percentuais dos vereadores sobre os fatores que se constituem ameaças ao regime democrático. 


\section{Tabela 12 \\ Fatores que se constituem ameaças a democracia \\ Grande Vitória (ES), 2015}

\begin{tabular}{lccc} 
Ameaças & Sim & Não & TOTAL \\
\hline Ganância das elites & 82,8 & 17,2 & $\mathbf{1 0 0 , 0}$ \\
Desigualdade de renda & 82,8 & 17,2 & $\mathbf{1 0 0 , 0}$ \\
Baixa escolaridade & 81,0 & 19,0 & $\mathbf{1 0 0 , 0}$ \\
Desrespeito aos direitos humanos & 82,8 & 17,2 & $\mathbf{1 0 0 , 0}$ \\
Agitação social & 36,2 & 63,8 & $\mathbf{1 0 0 , 0}$ \\
Corrupção nos órgãos públicos & 86,2 & 13,8 & $\mathbf{1 0 0 , 0}$ \\
Violência e o crime organizado & 79,3 & 20,7 & $\mathbf{1 0 0 , 0}$ \\
Problemas com segurança pública & 63,8 & 36,2 & $\mathbf{1 0 0 , 0}$ \\
Interferência do Judiciário em assuntos políticos & 55,2 & 44,8 & $\mathbf{1 0 0 , 0}$ \\
\hline
\end{tabular}

Fonte: Elaboração própria a partir da pesquisa do NPSA/UVV.

O que podemos perceber na tabela acima é que, para os vereadores entrevistados, as nove situações ameaçam fortemente a democracia: a) corrupção nos órgãos públicos, ganância das elites, desigualdade de renda, desrespeito aos direitos humanos, baixa escolaridade, violência e crime organizado, problemas com segurança pública, interferência do Judiciário em assuntos políticos, agitação social com, respectivamente, 86,2\%, 82,8\%, 82,8\%, 82,8\%, 81,0\%, 79,3\%, 63,8\%, 55,2\% e 36,2\%. Das nove situações, duas delas chamaram a nossa atenção.

A primeira diz respeito à corrupção nos órgãos públicos, pois reflete a atual situação política do Brasil, em que a operação Lava-Jato vêm revelando o quanto a corrupção está engendrada nos órgãos públicos com envolvimento de membros da classe política. Tal percepção ganhou mais peso quando fizemos três perguntas: i) - Falta punição judicial aos políticos eleitos envolvidos em atividades ilícitas? 94,8\% reiteraram que 'sim', ii) Falta punição política aos políticos eleitos envolvidos em atividades ilícitas? 93,1\% afirmaram que 'sim' e iii) Falta punição moral aos políticos eleitos envolvidos em atividades ilícitas? $87,9 \%$ certificaram que 'sim'. Os percentuais revelam por ora que faltam punições, sejam elas por parte do Judiciário, das siglas partidárias e da própria sociedade civil, aos envolvidos em atividades ilícitas.

A segunda questão que chamou nossa atenção diz respeito à agitação social (protesto), que para $63,8 \%$ dos entrevistados acham que ela não ameaça a democracia. Talvez eles achem, como muitos analistas enxergam - por exemplo, Scott Mainwaring ${ }^{8}$ que os protestos são substâncias societais que revigoram a democracia.

\footnotetext{
${ }^{8}$ Disponível em: <http://epoca.globo.com/tempo/noticia/2015/03/bscott-mainwaring-bprotestos-podemrevigorar-democracia.html>.Acesso em: 19 ju.2016.
} 


\section{CONCLUSÕES}

Ao longo do texto estudamos algumas variáveis vinculadas à origem social, ao perfil de carreira e à percepção política da elite local de alguns municípios da Região Metropolitana da Grande Vitória (Vitória, Vila Velha, Serra e Cariacica), Estado do Espírito Santo. Consideramos as variáveis aqui estudadas relevantes para o estudo da elite local, pois elas, de acordo com Perissinotto (2012, p. 191), "[...] definem a visão de mundo dos seus membros, suas intenções e, por conseguinte, contribuem para definir o conteúdo substantivo de suas decisões".

O nosso recorte temporal foi o ano de 2015 e as técnicas de coleta e a análise dos dados foram respaldadas nos principais métodos de pesquisa nas Ciências Sociais. Acreditamos que as indagações levantadas na Introdução (Quem nos governa? Que pessoas são essas que tomam as principais decisões no âmbito municipal? Qual o perfil delas? O que elas pensam sobre a democracia?) foram respondidas com as dimensões (II, III e IV) abordadas ao longo do texto, possibilitando identificar a existência de vários filtros sociológicos para desenhar a figura do parlamentar municipal.

A Dimensão II (Atributos adscritos e adquiridos dos vereadores) procurou examinar os atributos adscritos e adquiridos dos membros das elites locais: é homem; o que não gerou nenhuma estranheza; com idade entre 40 a 59 anos, um membro considerado 'velho' dentro da classe política; de cor branca, que também não causou nenhum espanto; possui o ensino médio completo; é funcionário público e é católico em suas atividades religiosas. As informações apreendidas por esta dimensão mostram que a elite local não é permeável à estrutura societal do munícipio, ou seja, é uma classe política fechada e homogênea que congrega determinados grupos sociológicos dando um caráter especial à elite local.

Já a Dimensão III (Perfis de carreira e partidário dos parlamentares) teve como objetivo analisar os perfis de carreira e partidário dos integrantes da classe política local: o vereador típico despertou para política no seio da sua igreja; possui filiação partidária entre os anos de 2011, 2012 e 2013; ocupou alguns cargos eletivos e não-eletivos em órgãos estratégicos; disputou de duas a três eleições; demonstra ambição progressiva, 
sonha alto, desejando ser prefeito ou deputado estadual; financiou a sua própria campanha no pleito de 2012; teve apoio dos familiares, das lideranças religiosas e comunitárias/sindicais e sua base eleitoral é concentrada em algum bairro, mas teve votos de pessoas vindas de grupos religiosos, movimentos sociais e associações profissionais. Os conhecimentos produzidos por esta dimensão mostram um parlamentar com capital político o suficiente para continuar a sua carreira no diminuto grupo local. A continuidade desse parlamentar fecha ainda mais a classe política local e quem desejar adentrar nesse grupo irá disputar com um político profissional da política.

A Dimensão IV (Percepções políticas dos vereadores) procurou discutir as percepções políticas dos membros das elites locais. Por um lado, são de centro na escala ideológica, para eles a democracia é preferível; ela está bastante/muito estável; vinculada à visão eleitoral, sendo o voto o principal instrumento que permite a participação do cidadão. Por outro lado, há um sentimento participacionista; a democracia é vista como sempre a melhor forma de governo, mas alguns fatores, entre eles a corrupção, ameaçam a democracia. As informações geradas por esta dimensão indicam que, na opinião dos vereadores entrevistados, hoje a democracia brasileira traz consigo alguns elementos sociopolíticos que permitem dizer que esse regime apresenta uma robustez societal, que dificilmente deixará de existir.

Finalizamos este artigo dizendo que, dada à importância do município e do vereador na nova ordem constitucional, é interessante pensar em uma agenda nacional de pesquisa sobre os perfis de carreira e as percepções políticas da elite local, pois os dados revelaram certas tendências empíricas que foram confirmadas por outros estudos ${ }^{9}$ que vêm discutindo o tema.

\section{REFERÊNCIAS}

ABRANCHES, Sérgio Hudson. A democracia brasileira vai bem, mas requer cuidados: proposições sobre democracia brasileira e o presidencialismo de coalizão. XIII Fórum Nacional, Estudos e Pesquisas, 2001.

ARAÚJO, Paulo Magalhães. Os parlamentares no Congresso Nacional: uma abordagem longitudinal e comparada do perfil de deputados e senadores brasileiros. Anais do 37 Encontro Anual da Anpocs. São Paulo: Anpocs, v. 37, 2013.

\footnotetext{
${ }^{9}$ Por exemplo, Braga, Leine e Sabbag (2015), Kerbauy (2014) e Felisbino e Kerbauy (2012).
} 
BRAGA, Maria do Socorro Sousa; LEINE, Priscila; SABBAG, Gustavo. Partidos e atuação na política local: autopercepção dos vereadores do Estado de São Paulo. 39 Encontro Anual da ANPOCS, 2015, Caxambu - MG. Anais... Caxambu - MG, 2015.

FELISBINO, Riberti de Almeida; KERBAUY, Maria Teresa Micelli. Os valores políticos da democracia nas opiniões dos vereadores de São Bernardo do Campo, Santo André e São Caetano do Sul. Revista Pensamento Plural, n. 10, v. 5, p. 155-180, 2012.

HUNTINGTON, Samuel. A terceira onda: a democratização no final do século XX. São Paulo: Ática, 1994.

HOUAISS. Dicionário Houaiss da língua portuguesa. Rio de Janeiro: Objetiva, 2009.

KELLER, Suzanne. O destino das elites. Rio de Janeiro: Forense, 1967.

KERBAUY, Maria Teresa Micelli (2014). Organização partidária e elites parlamentares municipais. BRASA XII, Brazilian Studies Association.

MAINWARING, Scott, Sistemas partidários em novas democracias: O caso do Brasil, Rio de Janeiro: Editora FGV, 2003.

MILLS, Charles Wright. La elíte del poder, 12ํㅡㄹção, México: Fondo de Cultura Econômica Editora, 2001.

MOISÉS, José. Álvaro. Democracia e confiança: por que os cidadãos desconfiam das instituições públicas? São Paulo: Editora EDUSP, 2010.

A desconfiança nas instituições democráticas. Campinas, Revista Opinião Pública, v. XI, n. 1, p. 33-63, 2005.

PERISSINOTTO, Renato M.; BRAUNERT, Mariana B. A direita, a esquerda e a democracia: os valores políticos dos parlamentares paranaenses (1995-2002). Revista Opinião Pública, Campinas, v. 12, n. 1, p. 114-135, 2006.

ROCHA, Marta Mendes; KERBAUY, Maria Teresa Miceli. Eleições, partidos e representação política nos municípios brasileiros, Juiz de Fora: Editora UFJF, 2014.

RODRIGUES, Leôncio Martins. Mudanças na classe política brasileira, São Paulo: Editora PubliFOLHA, 2006.

Quem é quem na constituinte: uma análise sócio-política dos partidos e deputados, São Paulo: Editora OESP-MALTESE, 1978.

SAMUELS, David. Financiamento de campanhas no Brasil e propostas de reforma. In: SOARES, Gláucio Ary Dillon e RENNÓ, Lúcio Remuzat (orgs.). Reforma política: lições da história recente. Rio de Janeiro: FGV, p. 133-153, 2006.

SILVA, Bruno Fernando da; SILVA, Bruna Tays. Perfil social e ideologia partidária: uma análise do recrutamento dos candidatos a vereador em Curitiba (2012). Revista

Mediações, v. 20 v. 2, p. 340-365, 2015. 
TILLY, Charles. Democracia. São Paulo: Editora Vozes, 2013.

VIANNA, Andrea. Congresso de machos: participação feminina no parlamento estaciona. Agressões verbais denunciam o apreço que certos congressistas têm pelas mulheres, Brasília, Congresso em foco. Disponível em:

$<$ http://congressoemfoco.uol.com.br/noticias/congresso-de-machos/>. Acesso em: 17 jul. 2016.

\title{
NOTAS
}

\section{TÍTULO DA OBRA}

Democracia e Representação Local: perfis de carreira e percepções políticas de vereadores da Grande Vitória (ES).

\author{
Riberti de Almeida Felisbino \\ Doutor em Ciências Sociais \\ CEET Vasco Coutinho, Vila Velha (ES), Brasil \\ ribertialmeida@hotmail.com.br \\ Dhttps://orcid.org/0000-0001-9267-443X
}

\section{Paulo Magalhães Araújo}

Doutor em Ciência Política

Universidade Federal do Espírito Santo, Departamento de Ciências Sociais, Vitória (ES), Brasil

pauloaraujomagalhaes@gmail.com

(1) http://orcid.org/0000-0002-2541-3640

\section{FINANCIAMENTO}

Não se aplica.

\section{CONFLITO DE INTERESSES \\ Não aplicável}

\section{LICENÇA DE USO}

Os autores cedem à Em Tese os direitos exclusivos de primeira publicação, com o trabalho simultaneamente licenciado sob a Licença Creative Commons Attribution 4.0 Internacional (CC BY). Estra licença permite que terceiros remixem, adaptem e criem a partir do trabalho publicado, atribuindo o devido crédito de autoria e publicação inicial neste periódico. Os autores têm autorização para assumir contratos adicionais separadamente, para distribuição não exclusiva da versão do trabalho publicada neste periódico (ex.: publicar em repositório institucional, em site pessoal, publicar uma tradução, ou como capítulo de livro), com reconhecimento de autoria e publicação inicial neste periódico.

\section{PUBLISHER}

Universidade Federal de Santa Catarina. Programa de Pós-Graduação em Sociologia Política. Publicado no Portal de Periódicos UFSC. As ideias expressadas neste artigo são de responsabilidade de seus autores, não representando, necessariamente, a opinião dos editores ou da universidade.

\section{HISTÓRICO}

Recebido em: 26 de novembro de 2018

Aprovado em: 10 de maio de 2019 